\title{
Estudios
}

\section{EL CUIDADO DE LA CASA COMÚN. RELEYENDO «LAUDATO SI'»EN SU QUINTO ANIVERSARIO}

Fecha de recepción: 30 de abril de 2020

Fecha de aceptación: 25 de mayo de 2020

RESUMEN: Este artículo pretender ser una invitación a la lectura de la primera encíclica social del papa Francisco en su quinto aniversario. «El desafío urgente de proteger nuestra casa común — dice el papa - incluye la preocupación de unir a toda la familia humana en la búsqueda de un desarrollo sostenible e integral, pues sabemos que las cosas pueden cambiar». La primera parte de este artículo ofrece una presentación del contenido de la encíclica, iluminando las ideas principales y el encadenamiento de los diferentes capítulos: la actual crisis ecológica, el Evangelio de la creación, las raíces de la crisis, una ecología integral, propuestas de diálogo y acción, líneas para una educación y espiritualidad ecológicas. Nuestra relectura de Laudato si' incluye el resultado de la celebración del Sínodo sobre la Amazonia, la exhortación apostólica Querida Amazonia. Este artículo concluye mostrando que la idea trinitaria de la creación es el principio que nos invita a desarrollar una espiritualidad de la solidaridad global, porque «en el mundo todo está conectado».

PALABRAS CLAVE: papa Francisco; ecología integral; Laudato si’; Querida Amazonia; doctrina social de la Iglesia; teología de la creación; ecología espiritual.

*Universidad Pontificia Comillas: smadrigal@comillas.edu;

ORCID: https://orcid.org/0000-0001-6722-1690 


\section{The Care for the Common Home Rereading "Laudato Si'» on its Fifth Anniversary}

ABSTRACT: This paper aims to be an invitation for the reading of the first social encyclical of Pope Francis on its fifth anniversary. «The urgent challenge to protect our common home - says the Pope- includes a concern to bring the whole human family together to seek a sustainable and integral development, for we know that things can change». The first part of this article concerns the presentation of the content of the encyclical, highlighting the main ideas and the linkage between the successive chapters: the present ecological crisis, the Gospel of creation, the roots of the crisis, an integral ecology, some proposals for dialogue and action, the guidelines for an ecological education and spirituality. Our rereading of Laudato $s i$ includes the results of the celebration of the Synod on the Amazonian region, the apostolic exhortation, Querida Amazonia. This article ends by offering that the trinitarian idea of creation invites us to develop a spirituality of global solidarity, because «everything in the world is connected».

KEY WORDS: Pope Francis; integral ecology; Laudato si'; Querida Amazonia; Social Catholic Thought; theology of creation; ecological spiritualty.

El pasado 3 de marzo del año en curso el papa Francisco invitó a los católicos de todo el mundo a celebrar y participar en la semana Laudato si' (= LS), entre el 16 y el 24 de mayo, al cumplirse el quinto aniversario de la encíclica sobre la ecología integral. El lanzamiento de esta campaña volvía a hacer resonar el emotivo interrogante que la recorre de principio a fin: «¿Qué tipo de mundo queremos dejar a quienes nos sucedan, a los niños que están creciendo?» (LS 160) ${ }^{1}$.

El tema del cuidado de la casa común, como casi todos los temas del magisterio de Francisco, hunden sus raíces en su exhortación apostólica y escrito programático, Evangelii gaudium (= EG) ${ }^{2}$. Allí, en el capítulo dedicado a la dimensión social de la evangelización se sitúa una sección titulada «cuidar la fragilidad», donde se lee:

1 Antonio Spadaro. "Laudato si'. Guida alla lettura dell'enciclica di Papa Francesco". La Civiltà Cattolica 166/3, n. 3961 (2015): 3-22. Francisco. Carta encíclica Laudato si'. Sobre el cuidado de la casa común. Madrid: San Pablo, 2015.

2 Cf. Santiago Madrigal. "Fundamentos teológicos de la reforma eclesial en el proyecto del papa Francisco". En La Reforma y las reformas en la Iglesia, 353-287. Santiago de Compostela: Instituto Teológico Compostelano, 2017. 
«Hay otros seres frágiles e indefensos, que muchas veces quedan a merced de los intereses económicos o de un uso indiscriminado. Me refiero al conjunto de la creación. Los seres humanos no somos meros beneficiarios, sino custodios de las demás criaturas. Por nuestra realidad corpórea, Dios nos ha unido tan estrechamente al mundo que nos rodea, que la desertificación del suelo es como una enfermedad para cada uno, y podemos lamentar la extinción de una especie como si fuera una mutilación. No dejemos que a nuestro paso queden signos de destrucción y de muerte que afecten nuestra vida y la de las futuras generaciones»(EG 215).

\section{DE LA ENCÍCLICA LAUDATO SI' A LA EXHORTACIÓN APOSTÓLICA QUERIDA AMAZONIA}

Entre las palabras clave de Francisco puede escogerse un puñado de ellas que se agrupan e interactúan dentro de una misma constelación semántica: «casa común», «conversión ecológica», «cultura del descarte», «paradigma tecnocrático» ${ }^{3}$. Todos estos términos entran en una relación especial en el marco de la segunda encíclica del papa Bergoglio, Laudato si', firmada el 24 de mayo de 2015, al poco de comenzar su tercer año de pontificado al frente de la Iglesia católica. Su subtítulo nos indica el tema: sobre el cuidado de la casa común.

\subsection{Cuatro Rasgos Característicos de la ENCíClica Sobre La CRisis MEDIOAMBIENTAL}

Esta carta encíclica es un documento original desde varios puntos de vista. En primer término, son interesantes las observaciones sobre los destinatarios: Francisco quiere dirigirse a todos, o sea, «a cada persona que habita este planeta» (LS 3). Expresamente, se coloca en la estela del papa del Concilio Vaticano II que quiso dirigir su mensaje Pacem in terris al mundo católico «y a todos los hombres de buena voluntad». Y lo hace en contraste con los destinatarios de su primera exhortación, Evangelii gaudium, que eran «los miembros de la Iglesia en orden a movilizar un

3 Cf. Francesc Torralba. Diccionario Bergoglio. Las palabras clave de un pontificado. Madrid: San Pablo, 2019, 45-63; 69-77; 79-107; 261-273, respectivamente. 
proceso de reforma misionera todavía pendiente». En esta encíclica el papa intenta «entrar en diálogo con todos acerca de nuestra casa común» (LS 3), para proponer «un nuevo estilo de vida» (LS 16), una «ciudadanía ecológica» (LS 211), de modo que la humanidad aborde con garantías el futuro próximo. Si en los años del Concilio zozobraba la paz en medio de la crisis nuclear, lo que hoy afecta a la humanidad en su conjunto es el deterioro ambiental global.

En este sentido llama la atención esa especie de excusa en forma de interrogante que abre el capítulo segundo de la encíclica, El Evangelio de la creación: «¿Por qué incluir en este documento, dirigido a todas las personas de buena voluntad, un capítulo referido a convicciones creyentes?» (LS 62). Podemos decir anticipadamente que aquí se encuentra el fundamento bíblico de la «ecología integral» que reivindica este papa y que asume la forma de un humanismo integral desde los presupuestos cristianos. De nuevo con palabras de Evangelii gaudium: «Pequeños pero fuertes en el amor de Dios, como san Francisco de Asís, todos los cristianos estamos llamados a cuidar la fragilidad del pueblo y del mundo en que vivimos» (EG 216).

Aquí engarza una segunda originalidad de este documento: las encíclicas reciben su nombre de las dos palabras latinas que la principian, como Lumen fidei, la luz de la fe. Pero en esta ocasión el papa argentino ha escogido la lengua italiana, el cántico de san Francisco de Asís: Laudato si', mi' Signore - "Alabado seas mi Señor». Y declara: «Tomé su nombre como guía y como inspiración en el momento de mi elección como Obispo de Roma» (LS 10). El santo de Asís es el paradigma del cuidado de lo débil y de una ecología integral, el hombre que personifica «la preocupación por la naturaleza, la justicia con los pobres, el compromiso con la sociedad y la paz interior» y así desborda el lenguaje matemático y biológico y el cálculo económico para conectarnos «con la esencia de lo humano» (LS 11). La inspiración franciscana de la encíclica le imprime una clara vocación de universalidad que incorpora a su auditorio también a los no creyentes. Finalmente, san Francisco de Asís nos invita a reconocer la naturaleza como el libro (LS 12) en el que Dios nos habla (cf. Sb 13,5; Ro 1,20).

En tercer lugar, cabe señalar otra peculiaridad que es de índole ecuménica: las otras Iglesias y comunidades cristianas, y también las otras religiones, han desarrollado una reflexión sobre estas cuestiones. En los primeros compases la encíclica da la palabra al Patriarca Bartolomé. Este 
hombre se había expresado varias veces invitando a todos a reconocer «los pecados contra la creación»: destrucción de la diversidad biológica, degradación de la integridad de la tierra, contribución al cambio climático, contaminación de las aguas, del suelo, del aire (LS 8).

Finalmente, en esta invitación urgente a un diálogo sobre el desafío ambiental, Francisco apoya su llamada en los pronunciamientos de las conferencias episcopales de todo el mundo, plasmando así el espíritu de la colegialidad al que había apelado en su primera exhortación apostólica. La primera vez que esto ocurre en Laudato si' es para dar voz a los obispos de Sudáfrica: «Se necesitan los talentos y la implicación de todos para reparar el daño causado por el abuso humano a la creación de Dios» (LS 14).

\subsection{UNA CONVICCIÓN DE FONDO: «TODO ESTÁ CONECTADO»}

Esta línea de reflexión ha vuelto a ocupar el escenario eclesial con ocasión de la celebración del Sínodo regional sobre la Amazonia (6-27 de octubre de 2019), cuyo documento final se titula: Amazonia. Nuevos caminos para la Iglesia y para una ecología integral. La Amazonia, también llamada Panamazonia, ese espacio geográfico conformado por la cuenca del río Amazonas y de sus afluentes, se extiende por 9 países: Bolivia, Perú, Ecuador, Colombia, Venezuela, Brasil, Guyana, Surinam y Guayana Francesa. «En la actualidad — dice el documento- es la segunda área más vulnerable del mundo con relación al cambio climático por la acción directa del hombre» ${ }^{4}$. En una palabra, es un lugar donde se percibe con especial intensidad «el clamor de la tierra y el grito de los pobres» (n. 10-18).

Uno de los ejes fundamentales del pensamiento ecológico de Francisco es "la convicción de que todo está conectado", de modo que la crisis ambiental es una crisis socio-ambiental (LS 139); de ahí, la interrelación entre los pobres y la fragilidad del planeta (LS 16). Carece, pues, de sentido discutir sobre la prioridad de la pobreza o del clima, de la crisis social o de la crisis medioambiental. Para Francisco estas dos

${ }^{4}$ Asamblea Especial del Sínodo de los Obispos para la Región Panamazónica. Amazonía. Nuevos caminos para la Iglesia y para una ecología integral. Documento final. Madrid: San Pablo, 2019, n. 6. 
dimensiones son inseparables y deben ser abordadas conjuntamente, porque - como hemos de ver- tienen un mismo origen: las relaciones del ser humano con la realidad que le rodea, relaciones marcadas por el «paradigma tecnocrático», propio de un antropocentrismo agresivo y despótico que está esquilmando el planeta. He aquí la tesis fundamental de la encíclica:

«Hoy no podemos dejar de reconocer que un verdadero planteo ecológico se convierte en un planteo social, que debe integrar la justicia en las discusiones sobre el ambiente, para escuchar tanto el clamor de la tierra como el clamor de los pobres» (LS 49).

Se ha dicho que la «encíclica franciscana» o «encíclica verde», presentada oficialmente el 18 de junio de 2015, seis meses antes de la celebración de la Cumbre del Clima de París (COP21), es la que ha tenido una recepción más amplia en los ámbitos no religiosos y científicos. Fue acogida con entusiasmo por varios organismos internacionales, como la ONU, la FAO, o el Programa de Naciones Unidas para el Medio Ambiente (PNUMA). De hecho, el papa hizo coincidir su visita a la sede de la ONU en Nueva York con la sesión en la que se iba a aprobar la llamada Agenda 2030: Transformar nuestro mundo. Agenda 2030 para el Desarrollo Sostenible. En su discurso, el 25 de septiembre de 2015, haciendo uso de la encíclica, habló de la existencia de un verdadero «derecho del ambiente» y del ser humano como «una porción de ese ambiente», de modo que el daño que se inflige al ambiente es un daño a la humanidad:

«Los cristianos, junto a otras religiones monoteístas, creemos que el universo proviene de una decisión de amor del Creador, que permite al hombre servirse respetuosamente de la creación para el bien de sus semejantes y para gloria del Creador, pero que no puede abusar de ella y mucho menos está autorizado a destruirla. Para todas las creencias religiosas, el ambiente es un bien fundamental (LS 81). [...] El abuso y la destrucción del ambiente, al mismo tiempo van acompañados por un imparable proceso de exclusión. La exclusión económica y social es una negación total de la fraternidad humana y un gravísimo atentado a los derechos humanos y al ambiente $»^{5}$.

${ }^{5}$ Francisco. "Discurso a la 70. ${ }^{\text {a }}$ Asamblea General de las Naciones Unidas". En Palabra profética y misión. Homilías, discursos y testimonios, 41. Santiago de Chile: Copygraph, 2016. 
«Todo está conectado», de modo que la degradación del medio ambiente y el cambio climático es una llamada a todos, una interpelación «a la ciencia y a la religión, que aportan diferentes aproximaciones a la realidad» (LS 62). Y, ciertamente, es clara la sintonía de la «ecología integral» con algunos de los objetivos de la Agenda de Desarrollo Sostenible 2030 de las Naciones Unidas ${ }^{6}$.

Finalmente, hay que decir que la relectura de Laudato si' con su llamada a la conversión ecológica es una tarea de renovada actualidad: «El desafío urgente de proteger nuestra casa común — dice el papa-incluye la preocupación de unir a toda la familia humana en la búsqueda de un desarrollo sostenible e integral, pues sabemos que las cosas pueden cambiar» (LS 13) ${ }^{7}$. Por un lado, ha quedado atrás la celebración, en diciembre de 2019, de una nueva Cumbre del Clima en Madrid (COP25), en la que se ha vuelto a constatar la grave amenaza que el calentamiento global constituye para el futuro de la humanidad ${ }^{8}$. Por otro lado, de puertas adentro, como decíamos al principio, la comunidad eclesial se siente concernida por la conmemoración del quinto aniversario de Laudato si'. En suma, esta reflexión sobre el sentido humano de la ecología y la propuesta de un nuevo estilo de vida traza una línea de fondo que recorre los años de pontificado de Francisco desde su inicio hasta el momento actual, marcado funestamente por la grave crisis causada por la pandemia del coronavirus.

6 Julio L. Martínez. "Ética en la Universidad: el horizonte de la Agenda 2030 y de la Ecología integral”. Razón y Fe 279 (2019): 291-292. Cf. José María Larrú, coord. Desarrollo humano integral y Agenda 2030. Madrid: BAC, 2020.

7 Entre los numerosos comentarios, puede verse: Enrique Sanz, ed. Cuidar de la tierra, cuidar de los pobres. Santander: Sal Terrae, 2015; Enrique Figueroa. La ecología del Papa Francisco: un mensaje para un planeta y un mundo en crisis. Madrid: BAC, 2016; Tomás Trigo, ed. Cuidar la creación. Estudios sobre la encíclica Laudato si'. Pamplona: Eunsa, 2016; Humberto M. Yáñez, ed. Laudato si': linee di lettura interdisciplinare per la cura della casa comune. Roma: Gregorian \& Biblical Press, 2017; Federico Lombardi y Fernando Sánchez Campos. Laudato si'. El cuidado de la casa común, una conversión necesaria a la ecología humana. Madrid: BAC, 2018.

8 María Carmen Llasat. "COP25: Un aviso urgente a todas las personas de este planeta”. Razón y Fe 281 (2020): 29-42. 


\section{EL ANCLAJE DE LA ENCÍCLICA «SOBRE EL CUIDADO DE LA CASA COMÚN» EN EL MAGISTERIO SOCIAL DE LA IGLESIA}

Estamos ante la primera encíclica social del papa Bergoglio, que es además la primera encíclica sobre las cuestiones ecológicas y «se agrega -leemos en LS 15-al Magisterio social de la Iglesia». En último término, este texto quiere llamar a la concientización ante la gravedad de la crisis ambiental y cultural (LS 214). Por tanto, un primer valor innegable de este documento reside en su contribución a fomentar la conciencia ambiental entre los católicos y en el conjunto de los ciudadanos ${ }^{9}$. Ello no quiere decir que el problema medioambiental hubiera estado totalmente ausente hasta ahora. Muy al contrario, se le puede seguir la pista a la irrupción de la problemática ecológica en el magisterio desde Rerum novarum (1891) hasta nuestros días ${ }^{10}$. Así lo hace, si bien en unos breves trazos, la introducción al documento (LS 3-6), donde Francisco ha querido recordar algunas ideas fundamentales de sus predecesores.

\subsection{De Juan XXIII a Benedicto XVI}

La primera referencia es la encíclica Pacem in terris (1963) de S. Juan XXIII, que significó la aceptación por la Iglesia de la Declaración Universal de los Derechos Humanos. Este texto no solo rechazaba la guerra, sino que hacía una propuesta de paz en el momento de la amenaza de la guerra nuclear (LS 3). Ocho años después, S. Pablo VI se refirió en la carta apostólica Octogesima adveniens a la problemática ecológica, presentándola como «una consecuencia dramática» de la actividad descontrolada del ser humano: «Debido a una explotación inconsiderada de la naturaleza, (el ser humano) corre el riesgo de destruirla y de ser a su vez víctima de esta degradación» (LS 4). También habló de «una crisis ecológica bajo el efecto de la explosión de la civilización industrial» en el discurso ante la FAO (1970), subrayando «la urgencia y la necesidad de un cambio radical en el comportamiento de la humanidad», porque «los progresos científicos más extraordinarios, las proezas técnicas más

9 Cf. Eduardo Moyano. "Un ensayo sobre la Laudato si' y su contribución a la conciencia ambiental”. Revista de Fomento Social 73/3-4 (2018): 441-456.

10 Jaime Tatay. Ecología integral. La recepción católica del reto de la sostenibilidad: $1891(R N)-2015$ (LS). Madrid: BAC, 2018. 
sorprendentes, el crecimiento económico más prodigioso, si no van acompañados por un auténtico progreso social y moral, se vuelven en definitiva contra el hombre».

Esta preocupación aparece con más fuerza en los escritos de S. Juan Pablo II, ya desde Redemptor hominis (1979), su encíclica programática (LS 5). En sus Catequesis del año 2001 llamó a un «conversión ecológica global» y en la encíclica Centesimus annus (1991) abogó por «una auténtica ecología humana», recordando que el cuidado y la mejora del mundo exige cambios profundos en «los estilos de vida, los modelos de producción y consumo, las estructuras consolidadas de poder que rigen hoy la sociedad».

En esta misma línea se situó Benedicto XVI que renovó esta invitación a «eliminar las causas estructurales de las disfunciones de la economía mundial y corregir los modelos de crecimiento que parecen incapaces de garantizar el respeto al medio ambiente» (LS 6). En el capítulo cuarto de su encíclica Caritas in veritate (n. 43-52), ofrece un buen análisis sobre el desarrollo humano, los derechos y deberes medioambientales. Merece la pena citar un texto del papa Ratzinger, de la XLIII Jornada Mundial por la Paz (1 de enero de 2010), que recapitula perfectamente estos análisis donde la dimensión ética y el rechazo de una mentalidad consumista se asocian con el cuidado y la protección de la creación:

«Cada vez se ve con mayor claridad que el tema del deterioro ambiental cuestiona los comportamientos de cada uno de nosotros, los estilos de vida y los modelos de consumo y producción actualmente dominantes, con frecuencia insostenibles desde el punto de vista social, ambiental e incluso económico. Ha llegado el momento en que resulta indispensable un cambio de mentalidad efectivo, que lleve a todos a adoptar nuevos estilos de vida, "a tenor de los cuales, la búsqueda de la verdad, de la belleza y del bien, así como la comunión con los demás hombres para un desarrollo común, sean los elementos que determinen las opciones del consumo, de los ahorros y de las inversiones". Se ha de educar cada vez más para construir la paz a partir de opciones de gran calado en el ámbito personal, familiar, comunitario y político. Todos somos responsables de la protección y cuidado de la creación».

En suma, la reflexión de los últimos papas había detectado el problema de la sostenibilidad del planeta en sus distintas vertientes, natural, social, económica y antropológica. Con Laudato si', el desafío medioambiental ha entrado a formar parte del repertorio de cuestiones propias de la doctrina 
social de una manera sistemática y con el espíritu pastoral que el Concilio Vaticano II le había impreso: una reflexión resituada en el marco de la misión de la Iglesia, en diálogo con el pluralismo de cosmovisiones, avanzando desde una visión antropológica de inspiración cristiana ${ }^{11}$.

Con tono de recapitulación ha escrito Francisco en la constitución apostólica Veritatis gaudium (8 de diciembre de 2017) que, desde la Populorum progressio "la cuestión social se interpreta como un tema antropológico que afecta al destino de la vida humana». Y añade: «Esta es la clave fundamental de lectura que inspiró el sucesivo magisterio social de la Iglesia, desde la Laborem exercens hasta la Sollicitudo rei socialis, desde la Centesimus annus de Juan Pablo II, pasando por la Caritas in veritate de Benedicto XVI, hasta la Laudato $s i^{\prime} »^{12}$.

Con estos antecedentes y desde estos presupuestos, podemos concluir que la perspectiva de Laudato si' no es una mera reflexión ecológica, puesto que no se limita a los fenómenos del cambio climático o la degradación del planeta, sino que tiene una dimensión integral, de modo que la complejidad de la crisis ecológica y sus múltiples causas se afronta desde «la luz que ofrece la fe» (LS 63), aunque sin dejar al lado las ciencias y otras formas de sabiduría:

«Además, la Iglesia católica está abierta al diálogo con el pensamiento filosófico y eso le permite producir diversas síntesis entre la fe y la razón. [...] Esto se puede constatar en el desarrollo de la doctrina social de la Iglesia, que está llamada a enriquecerse cada vez más a partir de los nuevos desafíos».

\subsection{El itinerario discursivo de LaUdato si'}

En su primera encíclica social, Francisco ha querido desarrollar una «ecología integral». Así reza el título del capítulo cuarto, que ocupa un lugar destacado como se desprende de la descripción del capitulario propuesto (cf. LS 15):

${ }^{11}$ Cf. Ildefonso Camacho. "La Doctrina Social de la Iglesia en la senda abierta por el Concilio Vaticano II". En El Concilio Vaticano II. Una perspectiva teológica, editado por Vicente Vide y José Ramón Villar, 480. Madrid: San Pablo, 2013.

12 Francisco. Constitución apostólica Veritatis gaudium, sobre las Universidades y las Facultades eclesiásticas, 8 de diciembre de 2107, n. 2. 
1) el primero, Lo que está pasando a nuestra casa (LS 17-61), describe la actual crisis ecológica en sus principales aspectos;

2) el segundo, El Evangelio de la creación (LS 62-100), asume los elementos que ofrece la tradición judío-cristiana para fundamentar nuestro compromiso con el medioambiente;

3) el tercero, Raíz humana de la crisis ecológica (LS 101-136), analiza las raíces profundas de la situación actual de crisis ambiental;

4) el cuarto hace la propuesta de Una ecología integral (LS 137-162);

5) el quinto diseña Algunas líneas de orientación y acción (LS 163-201);

6) el sexto, Educación y espiritualidad ecológica (LS 202-246), propone pautas de maduración humana y cristiana para una conversión ecológica.

Vamos a proceder a una lectura esencial de este documento, que evidentemente no puede detenerse en todas sus dimensiones ni en todos sus ricos y variados matices. Ya hemos adelantado grosso modo sus principales contenidos y su tesis principal: la humanidad atraviesa una grave crisis ambiental y social, provocada por el uso egoísta de los recursos conforme al paradigma tecnocrático, que daña al planeta y genera una exclusión económica y social; la alternativa a ese paradigma tecnocrático es una ecología integral que restablezca el puesto del ser humano en la creación según el designio de Dios.

Con todo, para alcanzar una primera visión sintética de la encíclica cabe tomar en consideración el método ver-juzgar-actuar, como han sugerido algunos intérpretes ${ }^{13}$ : el ver correspondería al capítulo primero: análisis de la realidad desde los distintos saberes científicos; el momento de juzgar correspondería a los capítulos segundo y tercero, es decir, la iluminación desde la fe cristiana (teología de la creación) permite reconocer la raíz antropológica de la crisis ecológica; el momento del actuar correspondería a los capítulos cuarto, quinto y sexto, de modo que la propuesta de una ecología integral incluye una concreción que se plasma tanto en un

${ }^{13}$ Cf. Leonardo Boff. "La Magna Charta de la ecología integral: el grito de la tierra y el grito de los pobres". En Cuidar la madre tierra. Comentario a la encíclica Laudato si' del papa Francisco, AA. VV., 5-18. Madrid: San Pablo, 2015. Juan Carlos Scannone. Il Vangelo della Misericordia nello spirito di discernimento. L'etica sociale di papa Francesco. Città del Vaticano: Libreria Editrice Vaticana, 2017, 64-65. Mario de França Miranda. A reforma de Francisco. Fundamentos teológicos. San Pablo (Brasil): Paulinas, 2017, 92-106: capítulo 5, “Laudato si': uma abordagem teológica”. 
diálogo a todos los niveles (en la política internacional y en las políticas nacionales y locales) como en la promoción de un nuevo estilo de vida.

\section{UNA PROPUESTA DE ECOLOGÍA INTEGRAL: LA CUSTODIA DE LA CREACIÓN Y LA CUSTODIA DE LOS MÁS POBRES}

Nuestra lectura no será la de un científico, la de un geólogo o la de un economista, sino una aproximación desde la teología con el objetivo de sustanciar los aspectos fundamentales del pensamiento ecológico de Francisco. En este sentido, es muy significativo recuperar su primera homilía, un ya lejano 19 de marzo de 2013, al comenzar su ejercicio del ministerio petrino. En aquel momento, al glosar la figura de S. José, hizo una llamada "a todos los hombres y mujeres de buena voluntad: seamos "custodios" de la creación, del designio de Dios inscrito en la naturaleza, guardianes del otro, del medio ambiente» ${ }^{14}$. Aquella homilía, en la que no faltó la alusión a san Francisco de Asís, contenía ya in nuce la preocupación que palpita en la encíclica ecológica: «custodiar toda la creación, custodiar a todos, especialmente a los más pobres, custodiarnos a nosotros mismos».

\subsection{Considerar lo que le está pasando a nUestra casa común}

Antes de expresar cómo la fe cristiana aporta nuevas motivaciones para una conciencia sobre el cuidado de la naturaleza, la encíclica comienza respondiendo a la pregunta: ¿qué está ocurriendo en la casa común? (LS 17). Para ello, asume los datos científicos más recientes en materia ambiental para señalar los síntomas más graves del grito de la creación: la contaminación, el cambio climático y el calentamiento del planeta, la gestión del agua, la pérdida de biodiversidad, el deterioro de la calidad de vida. Ahora bien, son los más débiles, los excluidos, los que sufren los efectos de la degradación ambiental: «Tanto la experiencia común de la vida ordinaria como la investigación científica demuestran que los más

\footnotetext{
${ }^{14}$ Francisco. "Primera homilía del Papa Francisco (19/03/2013)". En Palabra profética y misión, 11-13.
} 
graves efectos de todas las agresiones ambientales los sufre la gente más pobre» (LS 48).

El objetivo de esta acumulación de datos sobre el deterioro de la casa común no es satisfacer la curiosidad, sino «tomar dolorosa conciencia, atrevernos a convertir en sufrimiento personal lo que le pasa al mundo, y así reconocer lo que cada uno puede aportar» (LS 19).

«Todo está conectado», y por ello se ha establecido una «inequidad planetaria»; sin embargo, no se quiere reconocer que "la degradación ambiental y la degradación humana y ética están íntimamente unidas» (LS 56). En suma: el papa se muestra profundamente impresionado por la debilidad de reacciones frente al drama de tantas personas y poblaciones provocado por el actual modelo de desarrollo, basado en «la alianza entre economía y tecnología» (LS 54), que acaba dejando fuera lo que no forma parte de sus inmediatos intereses, generando así, conforme a la «cultura del descarte» (LS 43), tantas y tantas formas de marginación, exclusión y discriminación inmisericordes. Por tanto, «no hay dos crisis separadas, una ambiental y otra social, sino una sola y compleja crisis socio-ambiental» (LS 139).

\subsection{ReConocer el COMPROMISO ECOLÓgICO QUE BROTA DE LA TEOLOGÍA DE LA CREACIÓN}

Una reflexión desde la perspectiva de la fe bíblica nos ayudará a los creyentes a «reconocer mejor los compromisos ecológicos que brotan de nuestras convicciones» (LS 64) ${ }^{15}$. Esta es la aportación del capítulo segundo que comienza con una lectura sapiencial de la Escritura: ¿qué dicen los relatos bíblicos acerca de la relación del ser humano con el mundo?

Los relatos de la creación nos enseñan, en primer lugar, «la inmensa dignidad» del ser humano, "creado por amor, hecho a imagen y semejanza de Dios (Gn 1,26)» (LS 65). La narración del Génesis sugiere que la existencia humana se desenvuelve en tres relaciones fundamentales: «la relación con Dios, con el prójimo y con la tierra» (LS 66). Por aquí aparece una segunda enseñanza muy importante. La ruptura de la armonía

15 Cf. Miguel Rubio. "Laudato si': Una teología de la creación en perspectiva ecológica”. Moralia 39 (2016): 89-117. Denis Edwards. "Earth as God's Creation. The Theology of the Natural World in Pope Francis' Laudato Si"'. Phronema 31 (2016): 1-16. 
entre el Creador, la humanidad y todo lo creado es el pecado, que ha nacido de la negativa a reconocernos como criaturas limitadas y del hecho de desnaturalizar el mandato de «dominar» la tierra (Gn 1,28) y de «labrarla y cuidarla» (Gn 2,15). San Francisco de Asís nos ofrece el ejemplo de una sanación de aquella ruptura, la reconciliación universal con todas la criaturas. En este momento, el papa quiere salir al paso de una acusación lanzada contra el pensamiento judío-cristiano, según la cual el hecho de la creación a imagen de Dios y el mandato de dominar la tierra constituirían la justificación de una explotación salvaje de la naturaleza a manos de un ser humano dominante y destructivo. Piensa el papa que una presentación inadecuada de la antropología cristiana ha podido dar pábulo al sueño prometeico de dominio sobre el mundo (cf. LS 116). En su refutación Francisco parte de esta doble afirmación: no somos Dios y la tierra es un don que nos precede y nos ha sido dado, y propone una exégesis de los textos bíblicos explicando cómo el lema «labrar y cuidar el jardín del mundo» implica en realidad «una relación de reciprocidad responsable entre el ser humano y la naturaleza» (LS 67).

Frente a un antropocentrismo despótico, el término clave es responsabilidad. Estamos llamados a hacer un uso responsable de las cosas, porque los demás seres vivos tienen un valor propio ante Dios creador. Y, sobre todo, el prójimo, hacia el que tenemos el deber de la custodia y del cuidado. Si se descuidan la relaciones con los demás, con Dios y con la tierra, desaparece la justicia y toda la vida está en peligro. En el profundo simbolismo de los relatos bíblicos (Caín y Abel, el relato de Noé) late la convicción actual de que todo está conectado y relacionado: el cuidado de nuestra propia vida y de nuestras relaciones con la naturaleza es inseparable de la fraternidad con los demás (LS 70). Por tanto, «la mejor manera de poner en su lugar al ser humano, y acabar con su pretensión de ser un dominador absoluto de la tierra, es volver a proponer la figura de un Padre creador y un único señor del mundo, porque de otro modo el ser humano tenderá siempre a querer imponer a la realidad sus propias leyes e intereses» (LS 75).

Un nuevo capítulo de enseñanzas se abre al contemplar el misterio del universo en una perspectiva que ya insinuaba san Francisco de Asís cuando «nos propone reconocer la naturaleza como un espléndido libro en el cual Dios nos habla y nos refleja algo de su hermosura y de su bondad» (LS 12). En este sentido añade la encíclica: «Dios ha escrito un libro precioso, "cuyas letras son la multitud de criaturas presentes en el 
universo" » (...). "Podemos decir que, "junto a la Revelación propiamente dicha, contenida en la Sagrada Escritura, se da una manifestación divina cuando brilla el sol y cuando cae la noche" " (LS 85). Estas palabras, tomadas de las Catequesis de S. Juan Pablo II, evocan una contraposición audaz que se remonta a S. Agustín, liber naturae y liber scripturae. Que el universo pueda ser contemplado como un libro, como una continua revelación de lo divino, depende de esta convicción:

«Para la tradición judío-cristiana, decir “creación” es más que decir naturaleza, porque tiene que ver con un proyecto del amor de Dios donde cada criatura tiene un valor y un significado. La naturaleza suele entenderse como un sistema que se analiza, comprende y gestiona, pero la creación sólo puede ser entendida como un don que surge de la mano abierta del Padre de todos como una realidad iluminada por el amor que nos convoca a una comunión universal» (LS 76).

Cierto es, por lo demás, que el pensamiento judío-cristiano desmitificó la naturaleza (LS 78), al no atribuirle un carácter divino, pero no la ha vaciado de sentido, de su mensaje y de su carácter sacramental. Entre una visión desencantada del universo y una visión sacralizada, Francisco, apoyándose en textos de S. Tomás, escribe que «esta presencia divina, que asegura la permanencia y el desarrollo de cada ser, "es la continuación de la acción creadora"» (LS 80). El arte divino que va inscrito en las cosas es lo que las mueve desde dentro hacia su fin último.

Ahora bien, la singularidad del ser humano que trasciende el ámbito físico y biológico y su novedad cualitativa como ser personal no debe llevarnos a pensar que las demás criaturas hayan de ser consideradas como meros objetos sometidos al dominio despótico e irresponsable del ser humano. He aquí uno de los aspectos más originales de esta teología de la creación que está inspirada en Teilhard de Chardin: la marcha del universo tiene su fin en la plenitud de Dios, «que ya ha sido alcanzada por Cristo resucitado, eje de la maduración universal» (LS 83). Es el tema teilhardiano del Cristo cósmico, el punto Omega, el lugar de convergencia de un mundo en evolución.

Por tanto, el respeto a la naturaleza no se funda en la pura preocupación frente a la escasez de recursos naturales para el futuro; no se trata de una mera cuestión de subsistencia y del porvenir del planeta, ni siquiera de una buena gestión de los recursos. Este planteamiento de la ecología sigue siendo utilitarista y antropocéntrico. Para Francisco, todas 
las criaturas de la naturaleza son respetables en la medida en que ellas están igualmente concernidas por la espera escatológica de la salvación en Cristo: «Todas avanzan, junto con nosotros y a través de nosotros, hacia el término común, que es Dios, en una plenitud trascendente donde Cristo resucitado abraza e ilumina todo» (LS 83).

Dos observaciones completan esta teología de la creación. En primer lugar, la idea de una "comunión universal». Todos los seres del universo, creados por el mismo Padre, estamos unidos por lazos invisibles en una «comunión sublime»: «Dios nos ha unido tan estrechamente al mundo que nos rodea, que la desertificación del suelo es como una enfermedad para cada uno, y podemos lamentar la extinción de una especie como si fuera una mutilación» (LS 89; cf. EG 215) ${ }^{16}$. Esto no significa una divinización de la tierra ni quitarle al ser humano el valor peculiar o negar la «preeminencia» de la persona. No cabe imaginar la unión íntima con los seres de la naturaleza si no hay ternura, compasión y preocupación por los seres humanos. "Todo está conectado. Por eso se requiere una preocupación por el ambiente unida al amor sincero hacia los seres humanos y a un constante compromiso ante los problemas de la sociedad» (LS 91).

Una segunda observación tiene que ver con una convicción del papa Bergoglio ya expresada antes, a saber, que la crisis es una sola, crisis social y crisis ambiental. En consecuencia, «todo planteo ecológico debe incorporar una perspectiva social que tenga en cuenta los derechos fundamentales de los más postergados» (LS 93), y dado que «la tierra es esencialmente una herencia común, sus frutos deben beneficiar a todos». En este contexto recurre a las encíclicas Laborem exercens y Sollicitudo rei socialis de S. Juan Pablo II para afirmar «el principio de la subordinación de la propiedad privada al destino universal de los bienes». Por tanto, cualquier acción que impida este destino común de los bienes, excluyendo a otros, personas o pueblos, contradice y socava «el primer principio de todo el ordenamiento ético-social». La conclusión del capítulo dedicado a la teología de la creación fija la mirada en Jesucristo:

«Para la comprensión cristiana de la realidad, el destino de toda la creación pasa por el misterio de Cristo, que está presente desde el origen de todas las cosas: "Todo fue creado por él y para él" $(\mathrm{Col} 1,16)$ [...]. Una Persona de la Trinidad se insertó en el cosmos creado,

${ }^{16}$ Cf. Denis Edwards. "'Sublime communion': The Theology of Natural World in Laudato Si”'. Theological Studies 77 (2016): 377-391. 
corriendo su suerte con él hasta la cruz. Desde el inicio del mundo, pero de modo peculiar a partir de la encarnación, el misterio de Cristo opera de manera oculta en el conjunto de la realidad natural, sin por ello afectar su autonomía» (LS 99).

\subsection{Pensar la raíz antropológica de la crisis: el paradigma tecnocrático}

El tercer capítulo de la encíclica quiere responder a este interrogante: ¿cuáles son la causas profundas de la crisis ecológica? De entrada señala que «hay un modo de entender la vida y la acción humana que se ha desviado y que contradice la realidad hasta dañarla» (LS 101). El problema de fondo es que el ser humano pueda recuperar su auténtico puesto en el universo; con este objetivo, el análisis pasa por dos momentos: la globalización del paradigma tecnocrático y las consecuencias del antropocentrismo moderno.

En el punto de partida se encuentra el desarrollo espectacular de la tecnología en los dos últimos siglos (desde el motor a vapor hasta la revolución digital y la biotecnología). El papa aprecia y reconoce los beneficios del progreso tecnológico y su aportación a la mejora de las condiciones y de la calidad de vida (LS 102-103). Sin embargo, esa creatividad de la tecnociencia tiene como contrapartida el hecho de que confiere «un gran poder, sobre todo a los que tienen el conocimiento y el poder económico para utilizarlo sobre el conjunto de la humanidad» en sus diversos campos: energía nuclear, biotecnología, informática, secuenciación del ADN, etc. (LS 104). En una palabra: se tiende a creer que «el bien y la verdad brotaran espontáneamente del mismo poder tecnológico y económico» (LS 105).

En este momento el papa jesuita echa mano de uno de sus autores preferidos, Romano Guardini, y apoya sus análisis sobre su obra El ocaso de la Edad Moderna (1950) para emitir este veredicto sobre lo que llama «el paradigma tecnocrático»: «El hecho es que "el hombre moderno no está preparado para utilizar el poder con acierto" ${ }^{17}$, porque el inmenso

17 Romano Guardini. El ocaso de la Edad Moderna. Madrid, 1958, 112. Es el autor más citado en la encíclica. Sobre Guardini en Laudato si', véase: Massimo Borghesi. Jorge Mario Bergoglio. Una biografía intelectual. Dialéctica y mística. Madrid: Encuentro, 2018, 143; 171-182. Bergoglio estuvo en la Facultad de Teología de Frankfurt en el año 1986 para realizar una tesis doctoral sobre R. Guardini, que nunca culminó. 
crecimiento tecnológico no estuvo acompañado de un desarrollo del ser humano en responsabilidad, valores, conciencia» (LS 105). Existe, por consiguiente, una desproporción entre el poder técnico y la madurez ética de quien debiera usarlo. En el libro mencionado y en su obra El poder (Die Macht, 1951), Guardini trazó un cuadro de la degradación y de la explotación de la naturaleza a manos de la industrialización y de la tecnología muy próximo a las reflexiones de Martín Heidegger, llegando al convencimiento de que «el poder sobre el propio poder es la cuestión antropológica fundamental de nuestro tiempo ${ }^{18}$. El influjo del teólogo ítalo-alemán sobre el papa Bergoglio se condensa en la crítica del modelo tecnocrático de la Modernidad, un paradigma sociocultural que patrocina un aumento indiscriminado de poder sin control. $¿$ En manos de quién está todo ese poder tecnológico y económico, descontrolado sin que «una ética sólida, una cultura y una espiritualidad» lo limite y lo embride?

El problema es, pues, de fondo: la humanidad ha asumido este paradigma homogéneo y unidimensional, en el que la mentalidad tecnocrática dominante concibe toda la realidad como un objeto ilimitadamente manipulable, alterando radicalmente la polaridad entre hombre y naturaleza (LS 106). Francisco explica la globalización del paradigma tecnocrático en estos términos:

«La intervención humana en la naturaleza siempre ha acontecido, pero durante mucho tiempo tuvo la característica de acompañar, de plegarse a las posibilidades que ofrecen las cosas mismas. Se trataba de recibir lo que la realidad de suyo permite, como tendiendo la mano. En cambio ahora lo que interesa es extraer todo lo posible de las cosas por la imposición de la mano humana, que tiende a ignorar u olvidar la realidad misma de lo que tiene delante. Por eso, el ser humano y las cosas han dejado de tenderse amigablemente la mano para pasar a estar enfrentados».

El paradigma de la tecnociencia genera la quimera de un crecimiento infinito o ilimitado, que lleva a «estrujar» hasta el límite los bienes del planeta. La aplicación de este modelo a la realidad humana y social no solo conduce a la degradación del ambiente, sino a la de la sociedad

Cf. Austen Ivereigh. El gran reformador. Francisco, retrato de un papa radical. Barcelona: Ediciones B, 2015, 270-285.

18 Borghesi. Jorge Mario Bergoglio. Una biografía intelectual, 176. 
en todas sus dimensiones. Y citando de nuevo a R. Guardini, apostilla: «De hecho, la técnica tiene una inclinación a buscar que nada quede fuera de su férrea lógica, y "el hombre que posee la técnica sabe que, en el fondo, esta no se dirige a la utilidad ni al bienestar, sino al dominio; el dominio en el sentido más extremo de la palabra"19. Por eso "intenta controlar tanto los elementos de la naturaleza como los de la existencia humana"» (LS 108).

Estas denuncias de la lógica impuesta por el dominio tecnocrático se concretan en dos ámbitos muy importantes, la economía y la política, impidiendo reconocer que «el mercado por sí mismo no garantiza el desarrollo humano integral y la inclusión social» (LS 109). Todas estas reflexiones desembocan en el reconocimiento de que el dominio, fruto del mito prometeico de la época moderna, surge de un exceso de antropocentrismo, que "paradójicamente, ha terminado colocando la razón técnica sobre la realidad, porque este ser humano - explica Francisco con ayuda de Guardini- " "ni siente la naturaleza como norma válida, ni menos aún como refugio viviente. La ven sin hacer hipótesis, prácticamente, como lugar y objeto de una tarea en la que se encierra todo, siéndole indiferente lo que con ello suceda"20» (LS 115).

El remedio está en la cura de esta desmesura antropocéntrica. La criatura humana está llamada a redescubrir su verdadero lugar en el mundo y su relación con la naturaleza, so pena de entenderse mal a sí mismo y acabar contradiciendo su propia realidad. Para Francisco, «la forma correcta de interpretar el concepto del ser humano como "señor" del universo consiste en entenderlo como administrador responsable» (LS 116). "No habrá una nueva relación con la naturaleza sin un nuevo ser humano. No hay ecología sin una adecuada antropología» (LS 118). Por consiguiente, el remedio radica en una nueva antropología, y Francisco rechaza la propuesta de algunas corrientes del ecologismo radical: «Un antropocentrismo desviado no necesariamente debe dar paso a un "biocentrismo", porque esto implicaría incorporar un nuevo desajuste que no solo no resolverá problemas, sino que añadirá otros». El compromiso del ser humano con respecto al mundo debe reconocer al mismo tiempo sus peculiares capacidades de conocimiento, libertad y responsabilidad. En palabras de Borghesi: «Antropocentrismo prometeico y biocentrismo

\footnotetext{
19 Romano Guardini. El ocaso de la Edad Moderna, 83-84.

20 Ibid., 83.
} 
deshacen el vínculo constitutivo entre el yo y el mundo. Olvidan que "todo está conectado" (LS 117), que "todo está relacionado" (LS 120)» ${ }^{21}$.

Por otro lado, la crítica al antropocentrismo desviado no debe relegar a un segundo plano las relaciones entre las personas. La crisis ecológica es una manifestación externa de la crisis ética, cultural y espiritual de la modernidad, de modo que «no podemos pretender sanar nuestra relación con la naturaleza y el ambiente sin sanar todas las relaciones básicas del ser humano» (LS 119). Una adecuada relación con el mundo creado no debe debilitar la dimensión social del ser humano ni tampoco su dimensión trascendente. Y esto no al modo del Todo-Uno de matriz panteísta, sino a partir de la relación personal, fundamental y paradigmática, entre el yo y su apertura al «Tú divino».

Frente al biocentrismo y a un antropocentrismo unilateral, «está pendiente el desarrollo de una nueva síntesis que supere falsas dialécticas de los últimos siglos» (LS 121). Desde esta perspectiva, antes de cerrar este capítulo tercero, el documento aborda dos problemas de primera magnitud. En primer término, la cuestión del trabajo, recordando, en la línea de las afirmaciones de S. Juan Pablo II en la encíclica Laborem exercens, que «en cualquier planteamiento sobre una ecología integral que no excluya al ser humano es indispensable incorporar el valor del trabajo» (LS 124). Una segunda cuestión está en relación con el problema de los límites de la investigación biológica (LS 130ss), dando paso a una reflexión acerca de la intervención humana sobre los vegetales y los animales.

\subsection{HaCia UNA ECOLOGía INTEGRAL COMO PARADIGMA DE JUSTICIA Y BIEN COMÚN}

Hemos llegado así, después de este largo recorrido, al capítulo central de la encíclica, el más breve, donde hace su propuesta: la única alternativa válida al paradigma tecnocrático es una «ecología integral». Recordemos que la expresión «ecología integral» aparece muy al comienzo, referida al modelo que representa san Francisco de Asís, ya que en él «son inseparables la preocupación por la naturaleza, la justicia con los pobres, el compromiso con la sociedad y la paz interior» (LS 10) ${ }^{22}$. He aquí una pri-

${ }_{21}$ Borghesi. Jorge Mario Bergoglio. Una biografía intelectual, 181.

22 Cf. Paul Valadier. "L' humanisme intégral selon le papa François". Études 4625 (2019): 87. 
mera descripción del adjetivo integral. En consonancia con la tradición de la doctrina social de la Iglesia, que habla en términos del desarrollo humano integral ${ }^{23}$, Francisco se propone abordar todos los factores de la crisis mundial desde los distintos aspectos y las diversas dimensiones humanas y sociales, porque «todo está conectado»:

«Es fundamental buscar soluciones integrales que consideren las interacciones de los sistemas naturales entre sí y con los sistemas sociales. No hay dos crisis separadas, una ambiental y otra social, sino una sola y compleja crisis socio-ambiental. La líneas para la solución requieren una aproximación integral para combatir la pobreza, para devolver la dignidad a los excluidos y simultáneamente para cuidar la naturaleza» (LS 139) ${ }^{24}$.

Dicho con un ejemplo sencillo: examinar las razones por las que se contamina un lugar determinado exige un análisis del funcionamiento de la sociedad, de su economía, de su comportamiento y de sus maneras de entender la realidad. A su juicio, las mejores iniciativas ecologistas siempre corren el riesgo de quedar atrapadas en la lógica del paradigma tecnocrático, porque buscar un remedio técnico a cada problema ambiental es «aislar cosas que en la realidad están entrelazadas y esconder los verdaderos y más profundos problemas del sistema mundial» (LS 111).

En consecuencia, este capítulo discurre a través de los distintos tipos de ecología: la ambiental, la económica y la social; la cultural y la de la vida cotidiana. Empecemos por la primera serie. Francisco enfatiza la dimensión de interconexión entre todas las cosas y si la ecología se ocupa de los organismos vivientes y el ambiente en el que se desarrollan, es decir, los llamados “ecosistemas» ${ }^{25}$, también hay que pensar y discutir sobre «las condiciones de vida y sobrevivencia de una sociedad con la

${ }^{23}$ Cf. Ildefonso Camacho. "Laudato si': el clamor de la tierra y el clamor de los pobres. Una encíclica más que ecológica”. Revista de Fomento Social 71 (2016): 59-79. Ahí señala (p. 68) el uso del término «integral» en la doctrina social de la Iglesia: en Gaudium et spes, 64, en Populorum progressio, 20-21, en Caritas in veritate, 21-22.30.

${ }^{24}$ La terminología ecología integral aparece en el documento de la Comisión Teológica Internacional (6 de abril de 2018), «En busca de una ética universal: Nueva perspectiva sobre la ley natural», n. 82. Cf. Rafael Amo. "Fundamentos de ecología integral”. Estudios Eclesiásticos 94 (2019): 9n4.

${ }_{25}$ Sobre el concepto de «ecosistemas» y los «sistemas abiertos» y su funcionamiento como principios explicativos de la interconectividad en la ecología integral de Laudato si', véase: Amo. "Fundamentos de ecología integral", 20-26. 
honestidad de poner en duda modelos de desarrollo, producción y consumo» (LS 138). El concepto de crecimiento económico ofrece una comprensión limitada de los procesos de producción, que tiende a reducirlo todo a cálculo de costos; hay que practicar una "ecología económica», que haga de la protección del medio ambiente una parte integrante del proceso de desarrollo. Francisco insiste en este punto: «Al mismo tiempo se vuelve actual la necesidad imperiosa del humanismo, que de por sí convoca a los distintos saberes, también al económico, hacia una mirada más integral e integradora» (LS 141). Esto afecta también al estado de salud de las instituciones de una sociedad, cuyo deterioro se traduce en pérdida de libertad, en injusticia y en violencia. De ahí, la necesidad de una «ecología social» (LS 142).

El papa hacer notar, por otro lado, que «junto al patrimonio natural hay un patrimonio histórico, artístico y cultural, igualmente amenazado» (LS 143). Ese patrimonio ha de ser protegido, ya que forma parte «de la identidad común de un lugar y una base para construir una ciudad habitable». En este sentido, la ecología supone el cuidado de las riquezas culturales de la humanidad, incorporando la perspectiva de los derechos de los pueblos y de las culturas. La cultura es el hábitat propio de cada grupo humano, desde donde ejerce su protagonismo frente a una visión consumista que tiende a homogeneizar las culturas y a debilitar su diversidad (LS 144). La desaparición de una cultura es comparable a la desaparición de una especie animal o vegetal. Por tanto, hay que prestar una especial atención a las comunidades aborígenes con sus tradiciones culturales (LS 146).

El último tipo de ecología es el de la vida cotidiana, la que nos atañe a todos, que aspira a una mejora integral en la calidad de vida humana analizando el espacio donde transcurre nuestra existencia: nuestra habitación, nuestra casa, nuestro lugar de trabajo, nuestro barrio, nuestra ciudad (LS 147).

Esta ecología integral, que contempla el cuidado de la «casa común» a través de los distintos tipos de ecología, culmina en dos principios importantes dentro de la ética social: el bien común y la justicia entre generaciones. Francisco afirma que «la ecología humana es inseparable de la noción de bien común» (LS 156), un concepto que describe echando mano del artículo 26 de la constitución pastoral Gaudium et spes: «El conjunto de condiciones de la vida social que hacen posible a las asociaciones y a cada uno de sus miembros el logro más pleno y más fácil de la 
propia perfección». En las condiciones actuales de la sociedad mundial, el principio del bien común se convierte «en una llamada a la solidaridad y en una opción preferencial por los más pobres» (LS 158). Finalmente, el papa define la justicia entre las generaciones como la noción del bien común extendida a las generaciones futuras. En esta solidaridad entre las generaciones no se trata «de una actitud opcional, sino de una cuestión básica de justicia, ya que la tierra que recibimos pertenece también a los que vendrán» (LS 159). Aflora en este marco la pregunta decisiva de la que habíamos partido: "¿Qué tipo de mundo queremos dejar a quienes nos sucedan, a los niños que están creciendo?»

Interrumpimos aquí nuestra lectura de la encíclica, dejando apuntada la hondura del problema que se abre a un humanismo integral: «La cultura ecológica no se puede reducir a una serie de respuestas urgentes y parciales a los problemas que van apareciendo en torno a la degradación del ambiente, el agotamiento de las reservas naturales y a la contaminación. Debería ser una mirada distinta, un pensamiento, una política, un programa educativo, un estilo de vida y una espiritualidad que conformen una resistencia ante el avance del paradigma tecnocrático» (LS 111).

Este humanismo integral o ecología humana es lo más opuesto a un repliegue antropocéntrico de la humanidad sobre sí misma. Se trata, por el contrario, de la apertura a la riqueza y a la complejidad de la realidad creada, signo de la grandeza del misterio de Dios: «Los cristianos estamos llamados a aceptar el mundo como sacramento de comunión, como modo de compartir con Dios y con el prójimo en una escala global. Es nuestra humilde convicción que lo divino y lo humano se encuentran en el más pequeño detalle contenido en los vestidos sin costuras de la creación de Dios, hasta en el último grano de polvo de nuestro planeta» (LS 9). Volveremos sobre ello antes de terminar. Pero ahora damos paso a otra reflexión que completa el pensamiento ecológico de Francisco, al hilo de la exhortación apostólica salida del Sínodo regional sobre la Amazonia.

\section{LA ASAMBLEA ESPECIAL DEL SÍNODO DE LOS OBISPOS PARA LA REGIÓN PANAMAZÓNICA}

El papa argentino dio muestras de su sensibilidad por el bioma panamazónico desde muy pronto, desde la primera hora de su pontificado, a su paso por Río de Janeiro en el verano de 2013. En su encíclica ecológica, 
la Amazonia y la cuenca fluvial del Congo aparecen como «esos pulmones del planeta repletos de biodiversidad», de singular importancia para la totalidad del planeta y para el futuro de la humanidad (LS 38). Poco después, durante el 2. ${ }^{\circ}$ Encuentro Mundial de Movimientos Populares, celebrado el 9 de julio de 2015 en Santa Cruz de la Sierra (Bolivia), expresó en referencia a Laudato si' el ruego de "defender la Madre Tierra», echando por delante esta seria denuncia:

«La casa común de todos nosotros está siendo saqueada, devastada y vejada impunemente. La cobardía en su defensa es un pecado grave. Vemos con decepción creciente cómo se suceden una tras otra cumbres internacionales sin ningún resultado importante. Existe un claro, definitivo e impostergable imperativo ético de actuar que no se está cumpliendo. No se puede permitir que ciertos intereses - que son globales pero no universales- se impongan, sometan a los Estados y organismos internacionales, y continúen destruyendo la creación $»^{26}$.

Posteriormente, en enero de 2018, durante su visita al territorio amazónico en Puerto Maldonado (Perú) denunció «las hondas heridas» que cargan los pueblos indígenas y reafirmó «una opción sincera por la defensa de la vida, de la tierra y de las culturas»: «Ustedes son memoria viva de la misión que Dios nos ha encomendado a todos: cuidar la casa común ${ }^{27}$. De esta forma el papa jesuita se venía anticipando a lo que iba a ser la Asamblea especial del Sínodo de los Obispos para la Región Panamazónica que se celebró en Roma.

\subsection{Sinodalidad y Amazonia}

En la fase preparatoria del Sínodo, la REPAM (Red Eclesial para la Amazonia) había dirigido el proceso inédito de escucha territorial en más de 260 puntos en toda la Amazonia a través de asambleas, foros, grupos de trabajo, que permitió la participación directa de unas 22.000 personas, en toda su gran diversidad eclesial y cultural de esta región. Por tanto, el Instrumentum laboris, o documento de trabajo, fue el resultado de esta

${ }^{26}$ Francisco. "Discurso al 2. ${ }^{\circ}$ Encuentro Mundial de Movimientos Populares". En Palabra profética y misión, 37.

27 Discurso, Encuentro con los pueblos de la Amazonia, Puerto Maldonado (Perú), 19 de enero de 2018. 
amplísima consulta, primer momento y expresión basilar de un proceso de sinodalidad. Vino seguidamente la celebración en Roma de la Asamblea Especial bajo la presidencia del papa, como un espacio de discernimiento, diálogo y elaboración de propuestas, con vistas a identificar los posibles caminos para la Iglesia y para una ecología integral en la Amazonia.

Entre el 6 y el 27 de octubre de 2019, obispos y representantes de Bolivia, Brasil, Colombia, Ecuador, Guayana Francesa, Guayana, Perú, Venezuela y Surinam, se dieron cita en la Ciudad Eterna. Una de las mayores novedades de este Sínodo, poniendo en práctica el deseo del papa expresado en la constitución apostólica Episcopalis communio, ha sido la ampliación del círculo de participantes ${ }^{28}$. La aplicación de este criterio desde el proceso de preparación había propiciado la presencia de toda su diversidad territorial, así como una amplia presencia de mujeres. En el aula sinodal se pudieron escuchar en toda su rica variedad las voces de los pueblos originarios, mujeres y hombres, que hicieron presente en el corazón de la cristiandad latina los relatos y las experiencias de las comunidades y de los pueblos amazónicos. El resultado final de esta Asamblea especial quedó recogido en el documento final: Amazonia. Nuevos caminos para la Iglesia y para una ecología integral.

Mauricio López, actual secretario de REPAM, señala que este Sínodo ha puesto un acento especial en la importancia de reconocer el territorio como lugar teológico, de modo que la periferia se constituye en fuente de luz para iluminar el centro. En suma, el Sínodo de los Obispos para la región Panamazónica debe entenderse como un esfuerzo de adaptación de la encíclica Laudato si' a una región concreta.

En la región panamazónica confluyen muchas de las graves cuestiones que había abordado la segunda encíclica del papa jesuita. La globalización, la degradación de la naturaleza, la desigualdad económica, la depredación, la marginación de los más vulnerables, la imposición de un «paradigma tecnocrático» en las decisiones políticas, la violencia y otros males terribles que atentan contra la Amazonia y afectan a la vida de las gentes que la habitan, se han convertido en objeto de la exhortación apostólica postsinodal Querida Amazonia (= QA) que Francisco firmó el 20 de febrero de $2020^{29}$.

${ }^{28}$ Cf. Alphonse Borras. "Episcopalis communio, mérites et limites d'une réforme institutionelle”. Nouvelle Revue Théologique 141 (2019): 66-83.

${ }_{29}$ Francisco. Querida Amazonia. Exhortación apostólica postsinodal. Madrid: BAC, 2020 


\subsection{Los SUEÑos de Francisco: La EXHORTACión apostólica POSTSINODAL QUERIDA AMAZONIA}

Esta exhortación está dirigida «al pueblo de Dios y a todas las personas de buena voluntad». En la introducción, en referencia al documento final del Sínodo, el papa declara el sentido de su exhortación con estas indicaciones: primero, no va a desarrollar todas las cuestiones ahí tratadas, tampoco pretende reemplazarlo o repetirlo; segundo, va a proponer una sintesis de sus grandes preocupaciones «que ayude y oriente a una armoniosa, creativa y fructífera recepción de todo el camino sinodal» (QA 2). Además, esta exhortación quiere ser la presentación oficial del documento final; ahora bien, en vez de citarlo, hace una invitación a su lectura íntegra (QA 3). En su exhortación, Francisco no habla de directrices, principios o desafíos, sino que ha optado por el lenguaje de los «sueños para la Amazonia» (QA 5). Sus cuatro capítulos corresponden a estos cuatro sueños: un sueño social, un sueño cultural, un sueño ecológico, un sueño eclesial (QA 7). Con un lenguaje fuertemente poético, con citas que van desde Pablo Neruda a Pedro Casaldáliga, este escrito hace una recensión de los temas principales de la encíclica sobre ecología integral en los tres primeros capítulos; el último lleva el sello de su exhortación programática.

El primero es el sueño social de una Amazonia «que luche por los derechos de los más pobres, de los pueblos originarios, de los últimos, donde su voz sea escuchada y su dignidad sea prometida» (QA 8-27). Esta sección se hace eco de la devastación ambiental de la Amazonia y las amenazas a la dignidad humana de sus poblaciones a manos de un nuevo colonialismo injusto y criminal. Por ello, retoma la idea directriz de Laudato $s i^{\prime}$ : un verdadero planteamiento ecológico es siempre un planteamiento social que integra la justicia en las discusiones sobre el medio ambiente para escuchar el clamor de la tierra y el clamor de los pobres (cf. LS 49).

El segundo es el sueño cultural de una Amazonia «que preserve esa riqueza cultural que la destaca, donde brilla de modos tan diversos la belleza humana». Enlazando con la ecología social, el segundo capítulo (QA 28-40) reivindica el poliedro amazónico de los distintos pueblos con «su identidad cultural y riqueza única en un universo pluricultural». Frente a la actual economía globalizada que tiende a homogeneizar las culturas hay que cuidar las raíces de ese gran tesoro cultural de la humanidad (cf. LS 144). 
El tercero es el sueño ecológico de una Amazonia «que custodie celosamente la abrumadora hermosura natural que la engalana, la vida desbordante que llena sus ríos y selvas»(QA 41-60). En este capítulo, especialmente sembrado de poesía, Francisco retoma el principio de interconectividad, «todo está conectado»(LS 16. 91. 117. 138. 240), afirmando su especial validez para un territorio como la Amazonia y para el buen funcionamiento de sus ecosistemas. No en vano, de la salud de su bioma depende el equilibrio planetario, pues «funciona como un gran filtro del dióxido de carbono, que ayuda a evitar el calentamiento de la tierra» (QA 48).

El cuarto es el sueño eclesial de "comunidades cristianas capaces de entregarse y de encarnarse en la Amazonia, hasta el punto de regalar a la Iglesia nuevos rostros con rasgos amazónicos» (QA 61-110). El hilo conductor del capítulo cuarto es la inculturación, con la tarea misionera de desarrollar una Iglesia con rostro amazónico; se trata, por tanto, de "crecer en una cultura del encuentro hacia una "pluriforme armonía" " (QA 61; cf. EG 220). Ahora Francisco apela a Evangelii gaudium, donde había explicado el camino de la inculturación en términos de una encarnación de la Iglesia y del Evangelio por la obra del Espíritu ${ }^{30}$.

Todo empieza con el insoslayable anuncio del kerygma (EG 164-165). En este punto Francisco remite a los núcleos centrales de síntesis que ofreció en el capítulo cuarto de su exhortación apostólica postsinodal Christus vivit: Dios te ama, Cristo te salva, el Espíritu da vida ${ }^{31}$. El papa argentino, que entiende la evangelización como inculturación, ha formulado esta convicción: «la gracia supone la cultura y el don de Dios se encarna en la cultura de quien lo recibe» (EG 115, cf. QA 68). Late aquí un doble movimiento: por un lado, "cuando una comunidad acoge el anuncio de la salvación, el Espíritu Santo fecunda su cultura con la fuerza transformadora del Evangelio» (EG 116); por otro, «el Espíritu Santo embellece a la Iglesia, mostrándole nuevos aspectos de la Revelación y regalándole un nuevo rostro» (EG 116). Ahora bien, a la hora de la inculturación lo que está en juego es «la auténtica Tradición de la Iglesia, que

${ }^{30}$ Sobre la inculturación en Evangelii gaudium, véase: Juan Carlos Scannone. La teología del pueblo. Raíces teológicas del papa Francisco. Santander: Sal Terrae, 2015, 219-232.

${ }^{31}$ Francisco. Christus vivit. Exhortación apostólica postsinodal a los jóvenes y a todo el Pueblo de Dios. Madrid: BAC, 2020, n. 111-130. 
no es depósito estático ni una pieza de museo, sino la raíz de un árbol que crece» (QA 66) $)^{32}$.

A partir de estas premisas la exhortación se adentra en la problemática de los caminos de una renovada inculturación del Evangelio en la Amazonia (QA 70ss). Dada la situación de pobreza y abandono de tantos de sus pobladores, la Iglesia está llamada a aportar una firme defensa de los derechos humanos desde la opción de Cristo por los más débiles y pobres, es decir, una inculturación social y espiritual, que sea inspiradora de una santidad amazónica. En segundo término, Francisco, que recuerda que en el Sínodo surgió la propuesta de un "rito amazónico», plantea una inculturación de la liturgia en los pueblos indígenas, tal y como había sido sugerido por el Concilio Vaticano II. En tercer lugar, siguiendo esta lógica, reflexiona sobre una inculturación de las estructuras y de los ministerios eclesiales tomando en consideración el déficit de sacerdotes y la situación de muchas comunidades privadas de la eucaristía dominical durante largos periodos. Como es sabido, esta fue una cuestión debatida y muy aireada en la prensa, que jaleó la cuestión de los viri probati que fue incluida en las resoluciones del documento final del Sínodo (n. 111). En su exhortación Francisco no menciona este punto. Desde la acuciante necesidad de ministros ordenados invita a promover la oración por las vocaciones y reclama que las religiosas y los laicos asuman responsabilidades importantes para el crecimiento y la maduración de las comunidades.

El silencio sobre esta cuestión de la ordenación de hombres casados, unida al silencio sobre la solicitud del diaconado permanente para la mujer (n. 103), se han convertido en el filtro de la recepción de la exhortación apostólica postsinodal. Aunque, por ahora, más que de recepción en sentido técnico, habría que hablar de reacciones. Mi impresión es que el papa presta oído a los temas polémicos sobre cambios eclesiales,

32 En nota a pie de página, cita un texto recurrente en la mente de Francisco a la hora de explicar el desarrollo doctrinal, el Commonitorium primum de S. Vicente de Lérins (cap. 23: PL 50, 668), que explicaba en su entrevista con A. Spadaro (2013) en estos términos: la doctrina cristiana "progresa, consolidándose con los años, desarrollándose con el tiempo, haciéndose más profunda con la edad» (ut annis scilicet consolidetur, dilatetur tempore, sublimetur aetate). Cf. Razón y Fe 268 (2013): 274-275. La cita se encuentra en otros lugares, como Laudato si' n. 121, o Veritatis gaudium, n. 3. Cf. Eduardo J. Echeverría. El Papa Francisco. El legado del Vaticano II. Bilbao: Desclée de Brouwer, 2017, 84-85. 
—rito amazónico, ministerios femeninos, viri probati-, y no rechaza ni excluye nada, porque las resoluciones del documento final son el resultado de un camino sinodal que sigue abierto. En suma, un aplazamiento de cuestiones polémicas, sobre las que no hay suficiente consenso; por eso, Francisco habla expresamente de «ampliar horizontes más allá de los conflictos» (cf. QA 104-105).

No está de más volver la vista sobre las indicaciones que ha dado en otro lugar: se trata de «aceptar sufrir el conflicto, resolverlo y transformarlo en el eslabón de un nuevo proceso» (EG 227), adquiriendo «un modo de hacer la historia, en un ámbito viviente donde los conflictos, las tensiones y los opuestos pueden alcanzar una unidad pluriforme que engendra nueva vida. No es apostar por un sincretismo ni por la absorción de uno en otro, sino en la resolución en un plano superior que conserva en sí las virtualidades valiosas de las polaridades en pugna» (EG 228).

Entretanto, el cardenal Hummes, presidente de REPAM, ha dado los primeros pasos para la constitución de un Organismo Episcopal Panamazónico que continuará promoviendo el camino sinodal entre las Iglesias de esta región y debe ser un instrumento clave en el discernimiento y en la aplicación de las conclusiones del documento final del Sínodo. Por su parte, Francisco ha dado un paso en esta línea, nombrando ( 8 de abril de 2020) una nueva comisión para el estudio de la diaconía femenina. Siguen en pie sus convicciones fundamentales acerca de la inculturación, de una Iglesia de «rostro amazónico» y «marcadamente laical». Y, sobre todo, sigue en pie su mensaje acerca de una ecología integral que, en medio de todas estas reacciones, ha pasado a un segundo plano, pero sigue demandando de todos una conversión radical.

\section{CONCLUSIÓN. UNA ESPIRITUALIDAD DE LA SOLIDARIDAD GLOBAL DEL UNIVERSO FUNDADA EN EL MISTERIO DE LA TRINIDAD}

Retomamos aquí, para concluir, la lectura de Laudato si' donde la habíamos dejado: ¿qué tipo de mundo queremos dejar en herencia a las próximas generaciones? Desde este interrogante vamos a reflotar algunos aspectos del último capítulo de la encíclica, que trata de la educación y espiritualidad ecológica y comienza así: «Muchas cosas tienen que orientar 
su rumbo, pero ante todo la humanidad necesita cambiar» (LS 202) ${ }^{33}$. Hay que apostar por otro estilo de vida, empezando por salir del paradigma consumista y utilitarista, que nos ofusca, nos hace autorreferenciales y nos impide la apertura al bien, a la verdad, a la belleza.

Francisco nos invita a educarnos en una alianza entre la humanidad y el ambiente y a recuperar los distintos niveles del «equilibrio ecológico» (LS 210): «el interno con uno mismo, el solidario con los demás, el natural con todos los seres vivos, el espiritual con Dios». Viene bien al caso la cita de Paul Ricoeur que se lee en otro lugar del documento: «Yo exploro mi propia sacralidad al intentar descifrar la del mundo» (LS 85) ${ }^{34}$; por consiguiente, la educación ambiental nos podría ayudar a dar el salto desde una ética ecológica hacia el Misterio. Los distintos ámbitos educativos (escuela, familia, catequesis) están llamados a crear los hábitos de una ciudadanía ecológica.

En este intento de renovar la humanidad, la fe cristiana es portadora de líneas de espiritualidad ecológica que nacen del Evangelio y alimentan «una pasión por el cuidado del mundo» (LS 216). El papa apela una vez más a san Francisco de Asís como modelo para la conversión integral de la persona, que refleja una sana relación con lo creado, esto es, una conversión ecológica. En la secuela del Santo de Asís, la espiritualidad cristiana propone un retorno a la simplicidad, a un crecimiento con sobriedad y una capacidad de gozar con poco (LS 222). Este cuidado de la naturaleza es parte de un estilo de vida que implica la capacidad de vivir juntos y en comunión y alumbre una civilización del amor y una cultura del cuidado.

En esta espiritualidad ecológica, los sacramentos ocupan un lugar privilegiado, pues señalan «cómo la naturaleza es asumida por Dios y se convierte en mediación de la vida sobrenatural» (LS 235). El cristianismo abraza la materia (agua, aceite, fuego) para el encuentro con Dios en el acto litúrgico. Merece la pena detenerse en esta afirmación: «En la Eucaristía lo creado encuentra su mayor elevación», porque «en la Eucaristía, todo el cosmos da gracias a Dios» (LS 236). Prolongando el misterio de la encarnación, la eucaristía adquiere un significado verdaderamente cósmico. No en vano Teilhard de Chardin había hablado de la misa del universo.

33 Fernando Echarri. "La inteligencia espiritual ecológica: un desafío para la educación ambiental del futuro”. Revista Española de Teología 87/3 (2017): 299-319.

34 Paul Ricoeur. Finitud y culpabilidad. Madrid 1967, 249. 
Ahora bien, la espiritualidad ecológica cristiana tiene su origen y su meta en el misterio de la Trinidad (cf. LS 238-240). Este fragmento constituye, a mi juicio, el corolario de todo el documento, porque ahí encontramos la fundamentación teológica del principio de interconectividad e interdependencia que asiste al cosmos creado: «Todo está conectado, y eso nos invita a madurar una espiritualidad de la solidaridad global que brota del misterio de la Trinidad» (LS 240).

Descifremos, a modo de recapitulación, el alcance de este postulado que muestra que los principios de ecología de la doctrina social de la Iglesia se han visto fecundados y notablemente enriquecidos desde la teología trinitaria y la teología de la creación. El principio «todo está conectado» asume, en primer lugar, la tendencia que se abrió paso desde mediados del siglo pasado para «concebir el planeta como patria y la humanidad como pueblo que habita una casa de todos»; se trata, por tanto, de «la interdependencia (que) nos obliga a pensar en un solo mundo, en un proyecto común» (LS 164). En segundo término, esa interconexión se verifica a nivel biológico, y es que "así como los distintos componentes del planeta -físicos, químicos, biológicos- están relacionados entre sí, también las especies vivas conforman una red que nunca terminaremos de reconocer y comprender» (LS 138). A un nivel más profundo, en el corazón de la teología de la creación emerge la idea de una «comunión sublime», según la cual «todos los seres del universo estamos unidos por lazos invisibles y conformamos una especie de familia universal» (LS 89). Ahora bien, esa unión íntima con los seres de la naturaleza demanda una especial relación «de ternura, compasión y preocupación hacia los seres humanos» porque "todo está conectado» (LS 91). Y bien, ¿qué tiene que ver todo esto con el misterio de la Trinidad? ¿De qué modo el Dios uno y trino es el principio de esa solidaridad global, de esa interdependencia o interconexión entre toda la realidad creada? La primera respuesta va dada en una teología de la creación que atribuye papeles distintos a cada una de las tres divinas Personas en el acto de la creación:

«El Padre es la fuente última de todo, fundamento amoroso y comunicativo de cuanto existe. El Hijo que lo refleja, a través del cual todo ha sido creado, se unió a esta tierra cuando se formó en el seno de María. El Espíritu, lazo infinito de amor, está íntimamente presente en el corazón del universo animando y suscitando nuevos caminos. El mundo fue creado por las tres Personas como un único principio divino, 
pero cada una de ellas realiza esta obra común según su propiedad personal» (LS 238) 35 .

En segundo lugar, «creer en un solo Dios que es comunión trinitaria lleva a pensar que toda la realidad contiene en su seno una marca propiamente trinitaria» (LS 239). En tercer lugar, «las Personas divinas son relaciones subsistentes, y el mundo, creado, según el modelo divino, es una trama de relaciones [...]. En el seno del universo podemos encontrar un sinnúmero de constantes relaciones que se entrelazan secretamente ${ }^{36}$ ». En cuarto lugar, «esto no sólo nos lleva a admirar las múltiples conexiones que existen entre las criaturas, sino que nos lleva a descubrir una clave de nuestra propia realización. Porque la persona humana más crece, más madura y más se santifica a medida que entra en relación, cuando sale de sí misma para vivir en comunión con Dios, con los demás y con todas las criaturas. Así asume en su propia existencia ese dinamismo que Dios ha impreso en ella desde su creación» (LS 240).

Es interesante comprobar que Francisco ha presentado este punto de llegada de Laudato si' como el punto culminante «en la formación de una cultura cristianamente inspirada», cuyo acento principal radica «en descubrir la huella trinitaria en la creación, pues hace que el cosmos en el que vivimos sea "una trama de relaciones", y en el que "es propio de todo ser viviente tender hacia otra cosa", favoreciendo "una espiritualidad de la solidaridad global que brota del misterio de la Trinidad"»(Veritatis gaudium, 4).

De todo ello resultan unos análisis que se anticipan de forma profética a la crisis causada por la pandemia de la COVID-19: por un lado, la interconexión, o cómo una crisis sanitaria puede provocar una crisis económica que, a su vez, produce una crisis social y, por último, una crisis existencial. Por otro, la unificación técnico-económica del mundo, que trajeron el capitalismo agresivo y el paradigma tecnocrático, ha generado una paradoja que el coronavirus ha hecho visible: la interdependencia entre los países, en lugar de favorecer un progreso en la conciencia de los pueblos, ha desatado egoísmos y nacionalismos. El virus desenmascara

${ }^{35}$ Cf. Denis Edwards. "Everything Is Interconnected': The Trinity and the Natural World in Laudato Si"'. The Australasian Catholic Record 94 (2017): 86-87.

${ }^{36}$ Cf. Tomás de Aquino. Summa Theologiae I, q. 11, art. 3; q. 21, art. 1, ad 3; q. 47, art. 3 . 
la ausencia de una conciencia planetaria y de solidaridad hacia los más débiles. ¡Qué lejos estamos de la globalización de la solidaridad!

Un último apunte. En plena crisis mundial causada por el coronavirus, el papa jesuita concedió al escritor y periodista británico Austen Ivereigh una entrevista. Una de las cuestiones planteadas sonaba así: « ¿Se puede entender la crisis y su impacto económico como una oportunidad de una conversión ecológica, de revisar prioridades y nuestros modos de vivir? ¿Ve una posibilidad de una sociedad y economía menos líquidas y más humanas? ${ }^{37}$.

Francisco, en su respuesta, llamó la atención sobre la fragilidad de nuestra memoria respecto de catástrofes muy recientes, como los graves incendios en Australia. Esas catástrofes parciales no han sido atendidas. El papa recitaba un dicho que ha repetido en varias ocasiones: «Dios perdona siempre, nosotros de vez en cuando, la naturaleza nunca». Invitaba, pues, a recuperar la memoria, de la mano del verso de Virgilio, «Meminisse iuvabit», y en la línea de los Ejercicios espirituales de san Ignacio de Loyola, para recuperar la memoria de la tradición y de las raíces y proceder así a una conversión con la memoria. Este es un tiempo para recuperar memoria. No es la primera peste de la humanidad ni será la última. Ante esta crisis que nos afecta a todos, ricos y pobres, respondiendo a los interrogantes del periodista, abría una reflexión que refleja algunas ideas clave de su encíclica sobre el cuidado de la casa común:

«Toda crisis es un peligro pero también una oportunidad. Y es la oportunidad de salir del peligro. Hoy creo que tenemos que desacelerar un determinado ritmo de consumo y de producción (Laudato si', 191) y aprender a comprender y a contemplar la naturaleza. Y conectarnos con nuestro entorno real. Esta es una oportunidad de conversión. Sí veo signos de conversión a una economía menos líquida, más humana. Pero no perdamos la memoria una vez que pasó esto, no archivarlo y volver a donde estábamos».

Es la hora de «descender al subsuelo, y pasar de la sociedad hipervirtualizada, sin carne, a la carne sufriente del pobre. Es una conversión que tenemos que hacer».

${ }_{37} \mathrm{El}$ texto de la entrevista fue publicado en el periódico ABC, 8 de abril de 2020, pp. 34-37. 


\section{REFERENCIAS}

Amo, Rafael. "Fundamentos de ecología integral". Estudios Eclesiásticos 94 (2019): 5-37. DOI: https://doi.org/10.14422/ee.v94.i368.y2019.001

Asamblea Especial del Sínodo de los Obispos para la Región Panamazónica. Amazonía. Nuevos caminos para la Iglesia y para una ecología integral. Documento final. Madrid: San Pablo, 2019.

Boff, Leonardo. "La Magna Charta de la ecología integral: el grito de la tierra y el grito de los pobres". En Cuidar la madre tierra. Comentario a la encíclica Laudato si' del papa Francisco, Leonardo Boff, Alex Zanotelli, Gaël Giraud, Chiara Giaccardi, Mauro Magatti, y Giacomo Costa, 5-18. Madrid: San Pablo, 2015.

Borghesi, Massimo. Jorge Mario Bergoglio. Una biografía intelectual. Dialéctica y mística. Madrid: Encuentro, 2018.

Borras, Alphonse. "Episcopalis communio, mérites et limites d'une réforme institutionelle". Nouvelle Revue Théologique 141 (2019): 66-88. DOI: https://doi.org/10.3917/nrt.411.0066

Camacho, Ildefonso. "La Doctrina Social de la Iglesia en la senda abierta por el Concilio Vaticano II". En El Concilio Vaticano II. Una perspectiva teológica, editado por Vicente Vide y José Ramón Villar, 473-523. Madrid: San Pablo 2013.

Camacho, Ildefonso. "Laudato si': el clamor de la tierra y el clamor de los pobres. Una encíclica más que ecológica”. Revista de Fomento Social 71 (2016): 59-79. DOI: https://doi.org/10.32418/rfs.2016.281.1359

Echarri, Fernando. "La inteligencia espiritual ecológica: un desafío para la educación ambiental del futuro". Revista Española de Teología 87, n. 3 (2017): 299-319.

Echeverría, Eduardo J. El Papa Francisco. El legado del Vaticano II. Bilbao: Desclée de Brouwer, 2017.

Edwards, Denis. "Earth as God's Creation. The Theology of the Natural World in Pope Francis' Laudato Si”. Phronema 31 (2016): 1-16.

Edwards, Denis. 'Sublime communion': The Theology of Natural World in Laudato Si"'. Theological Studies 77 (2016): 377-391. DOI: https:// doi.org/10.1177\%2F0040563916635119

Edwards, Denis. "'Everything Is Interconnected': The Trinity and the Natural World in Laudato Si"'. The Australasian Catholic Record 94 (2017): 81-92. 
Figueroa, Enrique. La ecología del Papa Francisco: un mensaje para un planeta y un mundo en crisis. Madrid: BAC, 2016.

Francisco. Exhortación apostólica Evangelii gaudium. La alegría del Evangelio. Sobre el anuncio del Evangelio en el mundo actual. Madrid: San Pablo, 2013.

Francisco. Carta encíclica Laudato si'. Sobre el cuidado de la casa común. Madrid: San Pablo, 2015.

Francisco. Palabra profética y misión. Homilías, discursos y testimonios. Santiago de Chile: Copygraph, 2016.

Francisco. Constitución apostólica Veritatis gaudium, sobre las Universidades y las Facultades eclesiásticas (8 de diciembre de 2107).

Francisco. Christus vivit. Exhortación apostólica postsinodal a los jóvenes y a todo el Pueblo de Dios. Madrid: BAC, 2019.

Francisco. Querida Amazonia. Exhortación apostólica postsinodal. Madrid: BAC, 2020.

França Miranda, Mario de. A reforma de Francisco. Fundamentos teológicos. San Pablo (Brasil): Paulinas, 2017.

Ivereigh, Austen. El gran reformador. Francisco, retrato de un papa radical. Barcelona: Ediciones B, 2015.

Larrú, José María, coord. Desarrollo humano integral y Agenda 2030. Madrid: BAC, 2020.

Llasat, María del Carmen. "COP25: Un aviso urgente a todas las personas de este planeta”. Razón y Fe 281 (2020): 29-42.

Lombardi, Federico, y Fernando Sánchez Campos. Laudato si'. El cuidado de la casa común, una conversión necesaria a la ecología humana. Madrid: BAC, 2018.

Madrigal, Santiago. "Fundamentos teológicos de la reforma eclesial en el proyecto del papa Francisco". En La Reforma y las reformas en la Iglesia, 353-387. Santiago de Compostela: Instituto Teológico Compostelano, 2017.

Moyano, Eduardo. "Un ensayo sobre la Laudato si' y su contribución a la conciencia ambiental". Revista de Fomento Social 73/3-4 (2018): 441456. DOI: https://doi.org/10.32418/rfs.2019.291-292.1512

Rubio, Miguel. “Laudato si': Una teología de la creación en perspectiva ecológica". Moralia 39 (2016): 89-117.

Sanz, Enrique, ed. Cuidar de la tierra, cuidar de los pobres. Santander: Sal Terrae, 2015. 
Scannone, Juan Carlos. La teología del pueblo. Raíces teológicas del papa Francisco. Santander: Sal Terrae, 2015.

Scannone, Juan Carlos. Il Vangelo della Misericordia nello spirito di discernimento. L'etica sociale di papa Francesco. Città del Vaticano: Librería Editrice Vaticana, 2017.

Spadaro, Antonio. "Laudato si'. Guida alla lettura dell'enciclica di Papa Francesco". La Civiltà Cattolica 166/3, n. ${ }^{\circ} 3961$ (2015): 3-22.

Tatay, Jaime. Ecología integral. La recepción católica del reto de la sostenibilidad: 1891 (RN) - 2015 (LS). Madrid: BAC, 2018.

Torralba, Francesc. Diccionario Bergoglio. Las palabras clave de un pontificado. Madrid: San Pablo, 2019.

Trigo, Tomás, ed. Cuidar la creación. Estudios sobre la encíclica Laudato si'. Pamplona: Eunsa, 2016.

Valadier, Paul. "L'humanisme intégral selon le papa François". Études 4625 (2019): 79-89.

Yáñez, Humberto M., ed. Laudato si': linee di lettura interdisciplinare per la cura della casa comune. Roma: Gregorian \& Biblical Press, 2017. 